\title{
Intrafamilial variation of the phenotype in Bardet-Biedl syndrome
}

Department of Ophthalmology, Central Hospital of Hedmark, Hamar, Norway

R Riise

Department of Ophthalmology, University Hospital of Lund, Sweden

$S$ Andréasson

K Tornqvist

Department of Pedodontics, School of Dentistry, Malmö, University of Lund, Sweden

M K Borgström

MRC, Human Genetics Unit, Western General Hospital, Edinburgh, UK A F Wright

Department of Medical Genetics, The John F Kennedy Institute, Glostrup, Denmark

N Tommerup

National Eye Clinic for the Visually Impaired, Copenhagen, Denmark T Rosenberg

Correspondence to: Dr Ruth Riise, Department of Ophthalmology, Central Hospital of Hedmark, N-2300 Hamar, Norway.

Accepted for publication 13 January 1997

Ruth Riise, Sten Andréasson, Margareta K Borgström, Alan F Wright, Niels Tommerup, Thomas Rosenberg, Kristina Tornqvist

\begin{abstract}
Aims-To describe the variation of the phenotype within families with several individuals with Bardet-Biedl syndrome. Methods-The phenotypes of affected siblings in 11 Scandinavian families were compared with two or more members who had at least three of the features: retinal dystrophy, polydactyly, obesity, hypogenitalism, and mental retardation. Individuals without retinal dystrophy were excluded.

Results-Intrafamilial variation of expressivity of the features obesity, polydactyly, abnormal radiograms of the extremities, hypogenitalism, short stature, paraplegia, and dental abnormalities was found. The retinal dystrophy varied with respect to both the onset of symptoms and the course of the disease. The morphology of the fundus, however, was consistent within the families. The disorder showed statistically significant genetic linkage to the BBS4 locus on chromosome 15 in the affected siblings in two of the families, but the clinical features in these patients did not differ from the other cases of Bardet-Biedl syndrome.

Conclusion-Comparison of siblings with the Bardet-Biedl syndrome showed variation of the typical features. In addition, the course of retinal dystrophy varied. No distinctive clinical features were found to separate the BBS4 phenotype from the remaining patients.

(Br f Ophthalmol 1997;81:378-385)
\end{abstract}

The diagnosis of syndromes is still mainly based on careful clinical examination. The occurrence of identical cases within a family further demonstrates the existence of a nosological entity.

The history of the delineation of BardetBiedl syndrome (BBS) is complex.

Solis-Cohen and Weiss ${ }^{1}$ compared their observations with those of Laurence and Moon $^{2}$ and Biedl, ${ }^{3}$ and defined the LaurenceBiedl syndrome with the main features retinitis pigmentosa, obesity, hypogenitalism, poly/ brachydactyly, and mental retardation (Table 1). The name of Bardet, ${ }^{4}$ who described three similar cases in 1920, was later added to the syndrome. Hutchinson, ${ }^{5}$ however, re-examined the patients described by Laurence and Moon and found neurological symptoms in three out of the four siblings. These cases were, there- fore, considered distinct from the cases of Bardet and $\mathrm{Biedl}^{6}$ and the syndrome was accordingly separated into the Laurence-Moon and Bardet-Biedl syndrome. Later Alström and coworkers described diabetes mellitus and nerve deafness together with retinal dystrophy, obesity, and hypogonadism in three members of two related families. ${ }^{7}$ This new clinical entity was later called Alström syndrome.

It has thus been customary to delineate patients with retinal dystrophy, obesity, and hypogenitalism into the Laurence-Moon, Bardet-Biedl, and Alström syndromes. The phenotypes generally taken to identify each are presented in Table 2.

Meanwhile, many of these patients have shown considerable variation of the clinical expression. $^{8-15}$

Recent molecular genetic studies have shown that patients identified with the BBS had genetic disorders mapped to four different chromosomes. ${ }^{16-19}$ The gene loci have been termed BBS1, BBS2, BBS3, and BBS4.

The purpose of this report is to evaluate the precision of the clinical definition of BBS by comparing the phenotypes in siblings who had retinal dystrophy plus at least two more of the remaining traditional cardinal signs of BBS: obesity, polydactyly, hypogenitalism, and mental retardation.

Since the disorder in four patients from two of the families was mapped to the BBS4 locus on chromosome 15, we separately describe the phenotype in each of these individuals.

Materials and methods

A total of 44 Scandinavian individuals were defined as having BBS if they had retinal dystrophy plus at least two more of the remaining traditional cardinal signs of the syndrome (obesity, polydactyly, hypogenitalism, and mental retardation) (Table 2). Among them were 11 families (four Danish, two Swedish, and five Norwegian) with two or more affected siblings. We accepted two signs as sufficient for diagnosis if a sibling had three of the cardinal signs. Retinal dystrophy was considered an obligatory finding ${ }^{20}$; consequently, individuals without this sign were excluded.

The present study comprises 25 affected people: 16 males and nine females with a mean age of 24.8 years (SD 11.4, range 3-39). Consanguinity was present in three of the families (Fig 1). Families V, VII, X, and XI are Danish; families II, IV, VI, VIII, and IX Norwegian; and I and III Swedish (Fig 1). 
Table 1 Features of the patients in the families described by various groups

\begin{tabular}{|c|c|c|c|c|c|}
\hline Authors & Laurence-Moon & Bardet & Biedl & Solis-Cohen Weiss & Alström \\
\hline No of patients in the family & 4 & 2 & 2 & 4 & 3 \\
\hline \multicolumn{6}{|l|}{ No of patients with features: } \\
\hline Retinal dystrophy & 4 & 2 & 2 & 4 & 3 \\
\hline Obesity & 2 & 2 & 2 & 4 & 3 \\
\hline Hypogenitalism & 4 & 2 & 2 & 3 & 1 \\
\hline Polydactyly & - & 2 & 2 & 2 & 0 \\
\hline Short stature & - & 2 & 2 & 3 & 0 \\
\hline Mental retardation & 3 & - & - & 2 & 0 \\
\hline Diabetes mellitus & 4 & - & 2 & 4 & 0 \\
\hline Nerve deafness & - & - & - & 1 & 3 \\
\hline Renal disease & - & - & - & - & 3 \\
\hline \multirow[t]{2}{*}{ Paraplegia } & - & - & - & 1 & 2 \\
\hline & 3 & - & 0 & - & - \\
\hline
\end{tabular}

- not described; $0=$ not found.
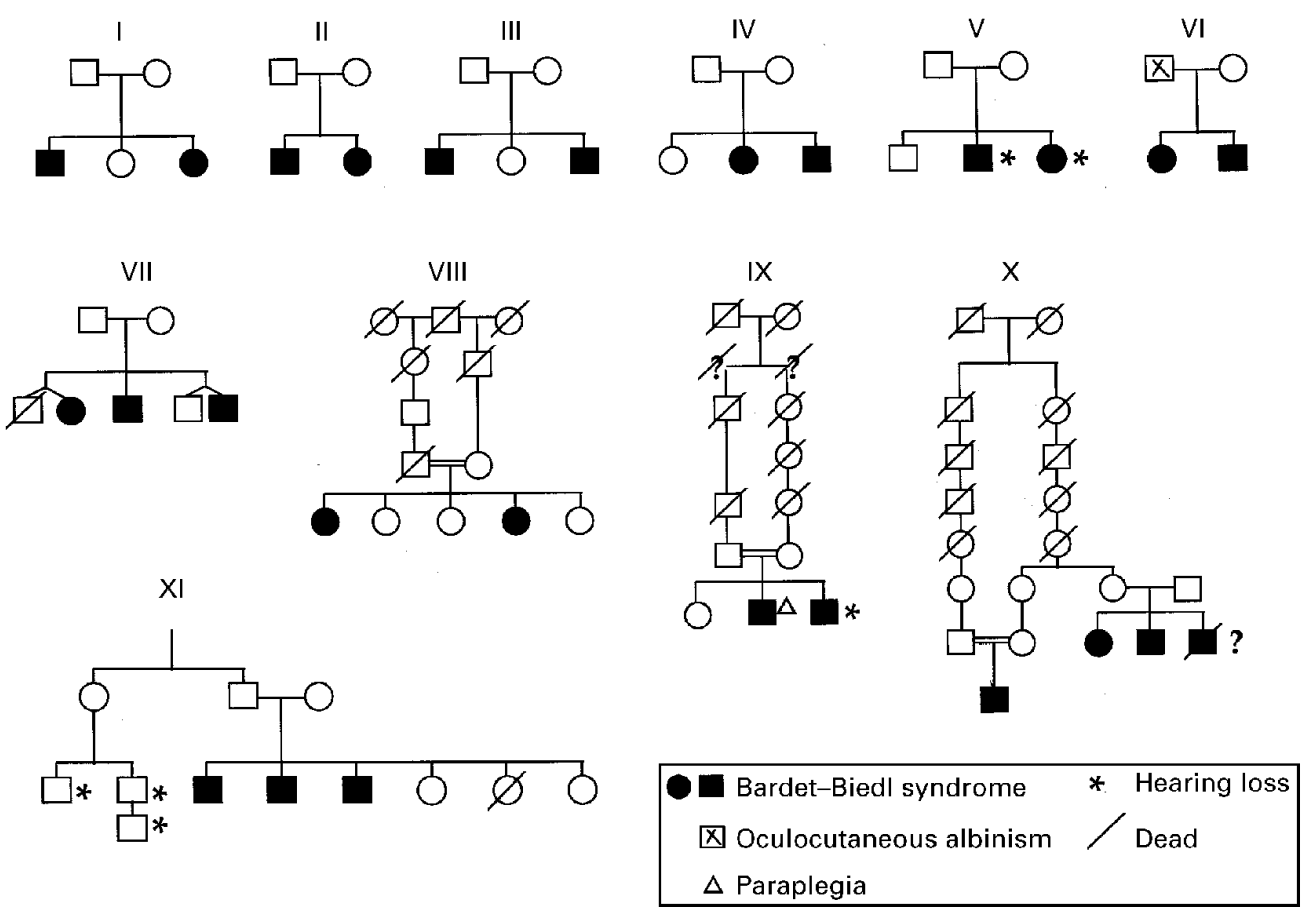

Figure 1 Pedigrees of 11 Scandinavian families with 25 cases with the Bardet-Biedl syndrome.

The individuals were located and contacted through the Swedish and Danish RP registers and the Norwegian LMBB Association and invited to participate in a 1 day outpatient examination by specialists in ophthalmology ( $\mathrm{R} \mathrm{R}$ and $\mathrm{K} \mathrm{T}$ ), electrophysiology ( $\mathrm{A}$ ), and dentistry (M K B) at the University Eye Clinic in Lund, Sweden.

The data were obtained by information from the patients, their relatives, doctors, hospital and school records, and the present clinical investigation.

The ophthalmic examination comprised assessment of best corrected visual acuity and

Table 2 Typical features in Laurence-Moon, Bardet-Biedl, and Alström syndromes

\begin{tabular}{llll}
\hline Feature & Laurence-Moon & Bardet-Biedl & Alström \\
\hline Retinal dystrophy & + & + & + \\
Mental retardation & + & $+/-$ & - \\
Obesity & + & + & + \\
Polydactyly & - & $+/-$ & +- \\
Hypogenitalism & + & - & + \\
Nerve deafness & - & $+/-$ & + \\
Diabetes mellitus & - & - & + \\
Paraplegia & + & + & + \\
Renal disease & - & & \\
\hline
\end{tabular}

cycloplegic retinoscopy. The refraction was expressed in spherical equivalents by adding one half the cylindrical correction to the spherical. The anterior segment was studied by slit-lamp examination. Direct and indirect ophthalmoscopy was supplemented by fundus photographs. Electroretinograms ${ }^{21}$ were obtained in all individuals except two, who refused to participate. The course of the retinal dystrophy was studied prospectively in six affected children from three of the families.

The ages for walking and speaking were taken as an indication of psychomotor development during childhood. An estimate of the mental status was based on intelligence tests from earlier records and the level of school and social performance. Further statements of the mental status were only made in cases with evident mental retardation.

The general systemic examination comprised measurements of height and weight. The presence of ataxia and paraplegia was estimated by inspection of the gait and by finger to nose test. The penis was evaluated by inspection of the phallus in six cases, while the 
remaining males or their relatives were questioned about the size. Hypogenitalism in men was defined as a penis less than $3-4 \mathrm{~cm}$ in prepubertal boys and less than $9 \mathrm{~cm}$ in adults ${ }^{22}$ and/or retention of testes. Previous presence of polydactyly was confirmed by inspection of the surgical scars supplemented by radiograms. ${ }^{23}$ The teeth were examined clinically and radiographically. ${ }^{24}$

DNA was purified for genetic linkage mapping by the methods described elsewhere ${ }^{25}$ and white blood cells were analysed for chromosome abnormalities. In addition, serum creatinine and testosterone (in eight males) were measured.

Parents and patients were questioned about onset of visual problems, renal disease, diabetes mellitus, and deafness.

The study was approved by the ethics committees in Denmark, Norway, and Sweden and the patients participated in the study after receiving written and verbal information.

\section{Results}

OCULAR FINDINGS

Retinal dystrophy was diagnosed in all cases in accordance with the allocation criteria to the study.

The age for the first sign of night blindness was on average 4.6 years (N 25, SD 3.9, range $0-16)$ with a maximum intrafamilial variation of plus or minus 6 years. The age for the first sign of visual impairment during daytime was 6.6 years $(\mathrm{N} 24, \mathrm{SD} 3.8$, range $0-16)$ with an intrafamilial variation of plus or minus 14 years. In family XI all affected siblings reported loss of central vision before or simultaneously with loss of their night vision. In family VII, one sibling showed signs of visual impairment and night blindness simultaneously at the age of 1 , another lost night vision at the age of 5 and became visually impaired at the age of 15 , and the third was visually impaired at 5 while night blindness presented itself at the age of 7 (Table 3).

The rate of decline of visual acuity (Fig 2 ) is illustrated by a 9 year prospective study of six affected children from families II, IV, and VIII with intrafamilial variation of expressivity for family IV.

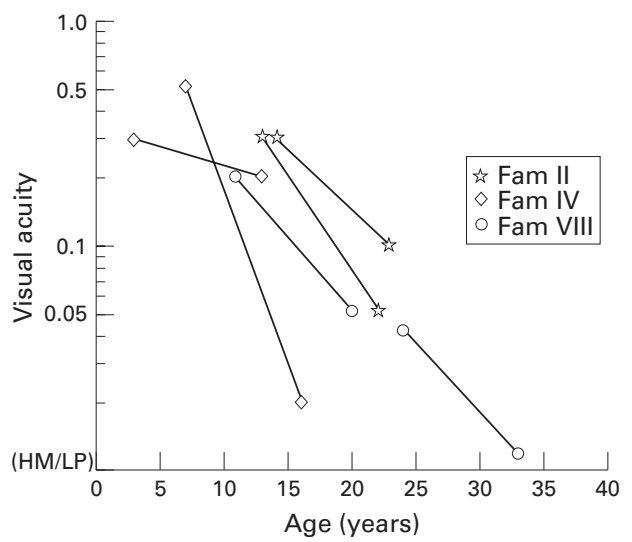

Figure 2 Visual acuity related to age measured with 9 year interval in three families with two affected siblings. The course of the disease varies in family IV.
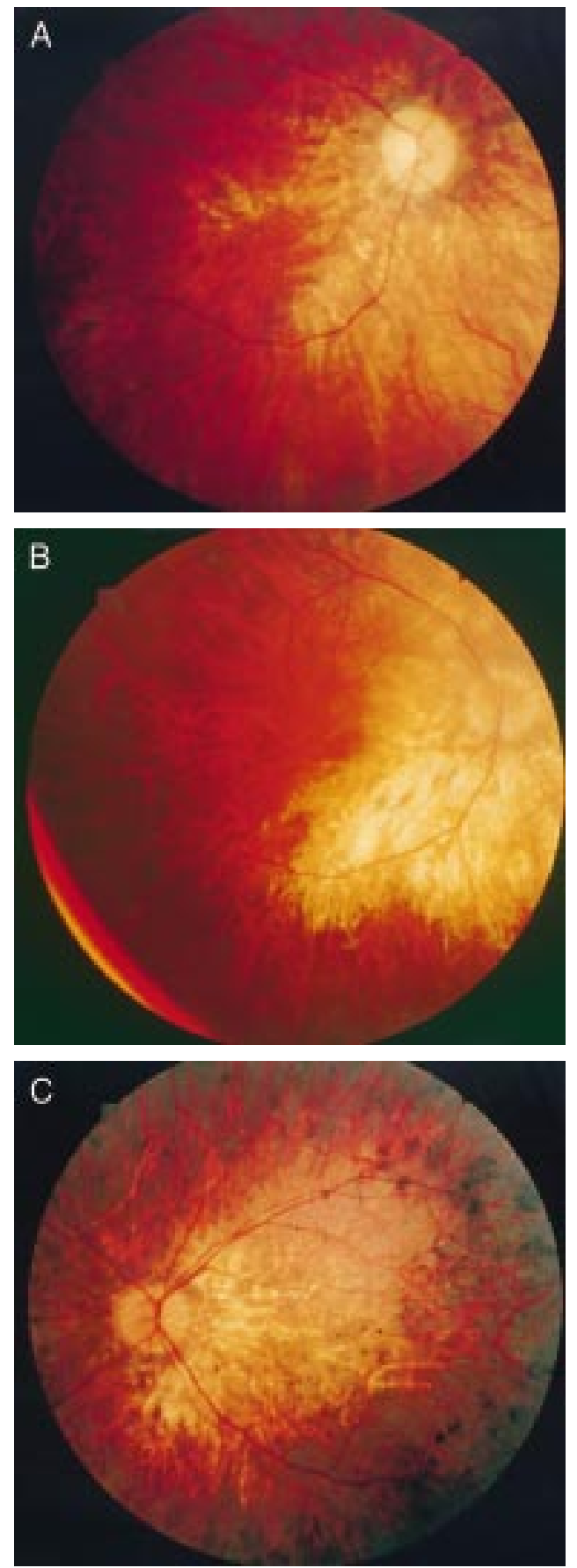

Figure 3 Ocular fundus of three siblings with BBS (family VII) with a waxy pale optic disc, atrophy of the choroid, narrow or obliterated vessels, and atypical pigmentation in the periphery.

In families II, IV, VII, and IX myopia was observed in all affected members (definition of myopia: spherical equivalent below $-0.5 \mathrm{D}$ ), while hypermetropia, myopia, and emmetropia were represented within the families $\mathrm{X}$ and XI (Table 3).

By examination of the fundus we noted variation of the amount and shape of the pigments and the amount of retinal and choroidal atrophy between but not within the families, when age was taken into consideration (Figs 3 and 4) (Table 3). 
Table 3 Ocular findings in the patients in 11 families with two or more sibs with Bardet-Biedl syndrome

\begin{tabular}{|c|c|c|c|c|c|c|c|c|c|c|c|}
\hline Family & $I$ & $I I$ & III & $I V$ & $V$ & $V I$ & $V I I$ & $V I I I$ & $I X$ & $X$ & $X I$ \\
\hline BBS locus & & & & & & & & 4 & 4 & & \\
\hline No of patients in the family & 2 & 2 & 2 & 2 & 2 & 2 & 3 & 2 & 2 & 3 & 3 \\
\hline Age range & $21-29$ & $22-23$ & $04-10$ & $13-16$ & $26-27$ & $06-09$ & $29-34$ & $20-33$ & $30-32$ & $07-36$ & $38-40$ \\
\hline \multicolumn{12}{|l|}{ No of patients with features: } \\
\hline Night blindness first sign & 2 & 0 & 2 & 1 & 2 & 0 & 1 & 1 & 2 & 0 & 0 \\
\hline Visual impairment first sign & 0 & 0 & 0 & 0 & 0 & 1 & 1 & 0 & 0 & 2 & 3 \\
\hline Night blindness and visual impairness & & & & & & & & & & & \\
\hline simultaneously & 0 & 2 & 0 & 1 & 0 & 0 & 1 & 1 & 0 & 1 & 0 \\
\hline Myopia & 0 & 2 & 0 & 2 & 0 & 0 & 3 & 1 & 2 & 1 & 1 \\
\hline Retinal bone spicules & 2 & 2 & 0 & 2 & 2 & 0 & 0 & 1 & 2 & 0 & 0 \\
\hline Cataract & 2 & 1 & 0 & 1 & 2 & 0 & 3 & 1 & 1 & 2 & 3 \\
\hline
\end{tabular}
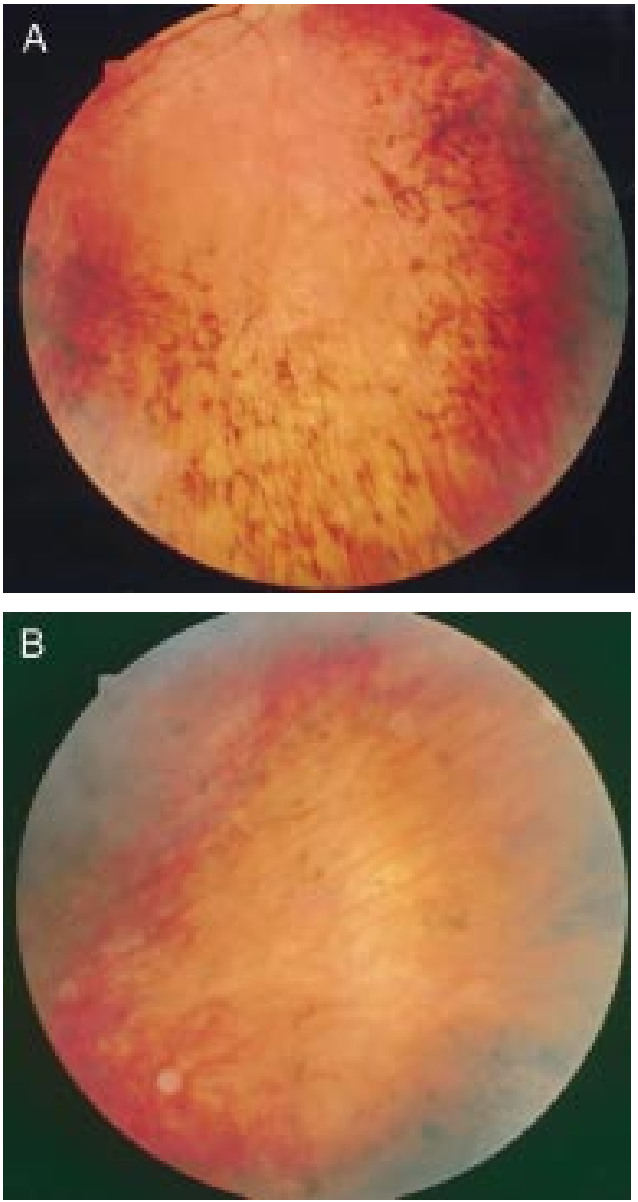

Figure 4 Ocular fundus of two siblings with BBS (family I) with typical bone spicules (blurred because of cataract).

Full field electroretinogram recordings showed no rod responses to dim blue light in any of the patients, but with a narrow band technique and computer averaging, residual cone responses could be measured in at least one eye in 15 of the individuals. ${ }^{21}$ No intrafamilial variation of the electroretinograms was noted (Fig 5).

\section{PSYCHOMOTOR DEVELOPMENT AND}

INTELLIGENCE

Three individuals from three different families did not walk at the age of 3 years and/or did not talk at 4 years of age. One person suffered from perinatal asphyxia and spastic tetraplegia and had no spoken language at the time of examination - that is, when he was 7 years old.

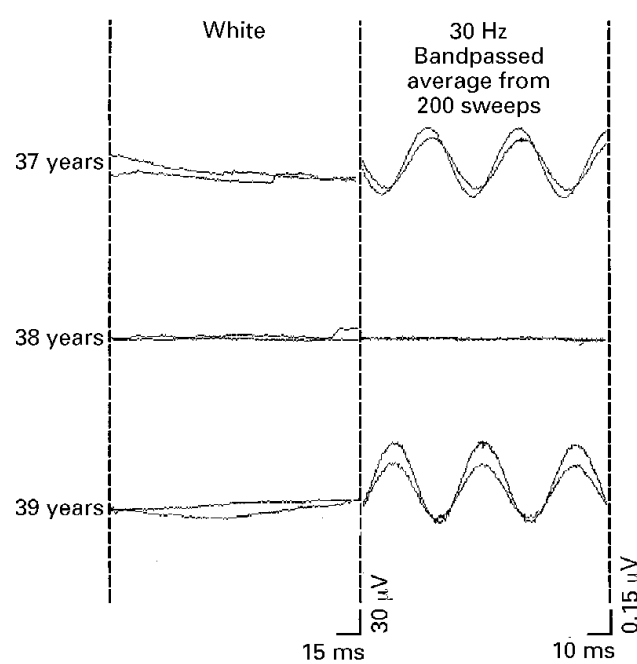

Figure 5 Full field electroretinograms from three affected siblings (family XI). ${ }^{21}$ No rod responses to dim blue light could be obtained. The cone ficker amplitude was less than $0.8 \mu \mathrm{V}$, which is a severely reduced or non-detectable response even with a bandpass filter. The small differences in the amplitudes are not significant.

Nine members of families V, VII, X, and XI had been classified as mentally retarded by intelligence tests at school, but the adult social performance of the patients in families VII, X, and XI did not confirm this classification. Generally, it was our impression that the majority of the 25 individuals functioned within the normal range of intelligence with no obvious differences between the affected siblings. In family IV both patients attended standard Scandinavian high schools. The male in family I worked in a computer company and one of the patients in family IX worked at the switchboard in a hospital (Table 4).

HEIGHT, WEIGHT, AND BODY MASS INDEX

Height was below the 2.5 percentile in one member of family $\mathrm{V}$ and one of family $\mathrm{X}$ (Table 4).

Obesity, defined by a body mass index (BMI) $>28 \mathrm{~kg} / \mathrm{m}^{2}$, was found in 22 of the 25 cases. The three individuals with normal weight were members of families VII and $\mathrm{X}$ (Table 4).

HANDS AND FEET

Twenty individuals had polydactyly at birth (Fig 6). The remaining five individuals without polydactyly belonged to families I, III, V, VIII, and XI (Table 4). 


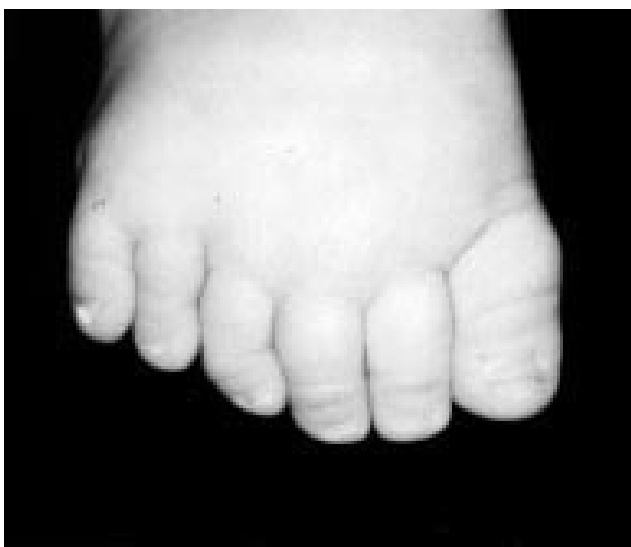

Figure 6 Polydactyly in the youngest patient in family III. His affected brother had no polydactyly.

Radiographical findings of hands and feet comprising short and broad metacarpals and phalanges, clinodactyly, or exostoses were found in all families. ${ }^{23}$ However, in families III and VII we documented cases with and without radiographical abnormalities (Table 4). No specific family pattern was found.

KIDNEYS AND URINARY PATHWAYS

In family XI all three siblings had gout. One member of families III, V, X, and XI had either a congenital anomaly or reduced function of kidneys (Table 4) verified by radiographical examination or increased serum creatinine, respectively.

NEUROLOGICAL FINDINGS

One of the siblings in family IX had episodes of paresis of his lower extremities caused by spinal stenosis, while his affected brother had no history of paresis. Both had obesity, hypogenitalism, polydactyly, and retinal dystrophy (Table 4).

GENITALIA

Thirteen of the 16 males had a small penis (Fig 7). Of these, seven had undescended testes and two had cryptorchism with a normal penis. Testosterone was reduced in the three brothers in family XI and was normal in the adult males in families I, VII, IX, and X. All the adult

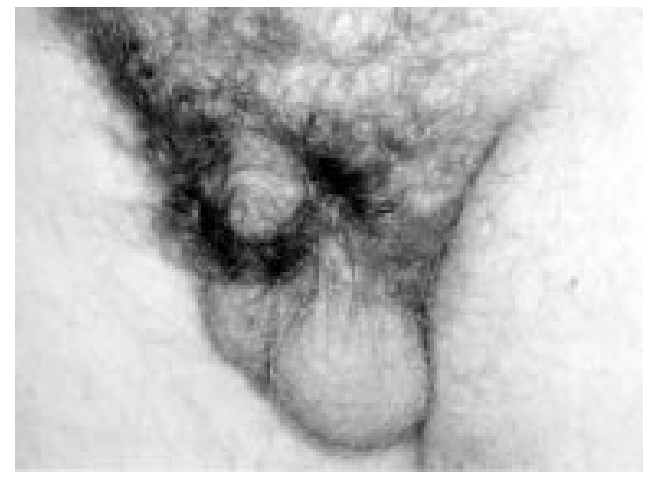

Figure 7 Micropenis in the male in family I. No hypogenitalism had been noted in his affected sister.

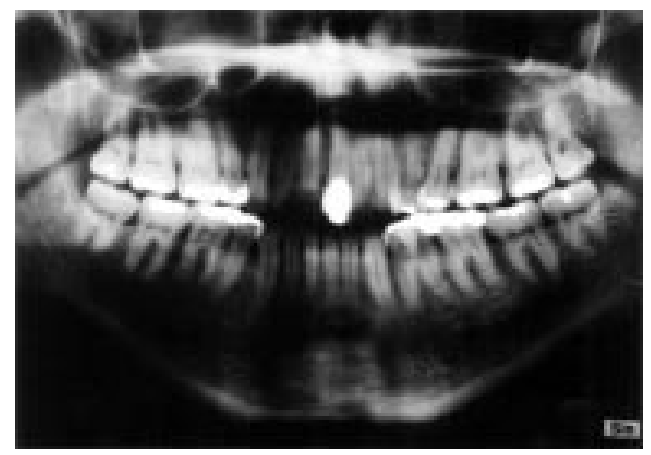

Figure 8 Hypodontia (congenitally missing teeth) in one of the affected males in family VII. The affected sister had no dental anomalies.

women had irregular menstrual periods. The female in family VII had given birth to a child; her affected brothers had a normal penis but one had cryptorchism. The woman in family V was reported to have small genitalia and moderate hirsutism (Table 4).

\section{TEETH}

Examination of the teeth showed higher frequencies of small teeth, hypodontia (congenitally missing teeth), and short roots. ${ }^{24}$ In family VII hypodontia was found in both affected males (Fig 8) but not in the affected sister. In families $\mathrm{V}$ and XI we also found affected siblings with and without dental anomalies (Table 4).

Table 4 The clinical signs in the patients in 11 families with two or more sibs with Bardet-Biedl syndrome

\begin{tabular}{|c|c|c|c|c|c|c|c|c|c|c|c|}
\hline Family & $I$ & $I I$ & $I I I$ & $I V$ & $V$ & $V I$ & $V I I$ & VIII & $I X$ & $X$ & $X I$ \\
\hline No of affected $M / F$ & $1 / 1$ & $1 / 1$ & $2 / 0$ & $1 / 1$ & $1 / 1$ & $1 / 1$ & $2 / 1$ & $0 / 2$ & $2 / 0$ & $2 / 1$ & $3 / 0$ \\
\hline BBS locus & & & & & & & & 4 & 4 & & \\
\hline \multicolumn{12}{|l|}{ No of patients with features: } \\
\hline Retinal dystophy & 2 & 2 & 2 & 2 & 2 & 2 & 3 & 2 & 2 & 3 & 3 \\
\hline Obesity & 2 & 2 & 2 & 2 & 2 & 2 & 1 & 2 & 2 & 2 & 3 \\
\hline Hypogenitalism & 1 & 1 & 2 & 1 & 2 & 1 & 1 & 0 & 2 & 2 & 3 \\
\hline Polydactyly & 1 & 2 & 1 & 2 & 1 & 2 & 3 & 1 & 2 & 3 & 2 \\
\hline Abnormal radiograms of & & & & & & & & & & & \\
\hline extremities & 2 & 2 & 1 & $1-$ & 2 & 2 & 2 & 2 & $1-$ & 3 & 3 \\
\hline Short stature & 0 & 0 & 0 & 0 & 1 & 0 & 0 & 0 & 0 & 1 & 0 \\
\hline Mental retardation & 0 & 0 & 0 & 0 & 2 & 0 & ? & $2 ?$ & 0 & 1 ? & ? \\
\hline Diabetes mellitus & 0 & 0 & 0 & 0 & 2 & 0 & 0 & 0 & 0 & 1 & 0 \\
\hline Nerve deafness & 0 & 0 & 0 & 0 & 2 & 0 & 0 & 0 & 0 & 0 & 0 \\
\hline Renal disease & 0 & 0 & 1 & 0 & 1 & 0 & 0 & 0 & 0 & 1 & 1 \\
\hline Paraplegia & 0 & 0 & 0 & 0 & 0 & 0 & 0 & 0 & 1 & 0 & 0 \\
\hline Abnormal teeth & 2 & 2 & - & $1-$ & 1 & - & 2 & 2 & $1-$ & $2-$ & 2 \\
\hline
\end{tabular}

$-=$ not described; $0=$ not found. 
Table 5 Exclusion and inclusion of linkage to BBS loci on chromosomes 11 (BBS1), 15 (BBS4), and 16 (BBS2) in 11 Scandinavian families with two to three affected members. ${ }^{25}$ The probability of linkage to the chromosome indicated is given in parenthesis

\begin{tabular}{lll}
\hline Family & $\begin{array}{l}\text { Linkage exclusion } \\
p<0.10\end{array}$ & $\begin{array}{l}\text { Linkage inclusion } \\
p>0.5\end{array}$ \\
\hline I BB22 & $11(0.03)$ & $16(0.55)$ \\
II BB12 & $11(0.05)$ & $11(0.54)$ \\
III BB30 & $16(0.07)$ & $15(0.83)$ \\
IV BB14 & $16(0.01)$ & $11(0.54)$ \\
V BB27 & $16(0.03)$ & \\
VI BB28 & $11(0.08)$ & $11(0.61)$ \\
VII BB24 & $15(0.02)$ & $15(0.95)$ \\
VIII BB18* & $11(0.04)$ & $15(0.94)$ \\
IX BB31* & $16(0.00)$ & $15(0.93)$ \\
X BB25/26* & $11(0.06)$ & $11(0.62)$ \\
XI BB23 & $11(0.00)$ & \\
\hline
\end{tabular}

${ }^{\star}$ Indicates a consanguineous family.

HEARING IMPAIRMENT

Both siblings in family $\mathrm{V}$ had perceptive hearing loss and indications of type 2 diabetes with marginal glucose tolerance test, increased proinsulin, and $\mathrm{HbA}_{1 \mathrm{c}}$ in serum. The female had polydactyly. Both had retinal dystrophy with photophobia from the age of 2 years, night blindness at 4-5 years, and visual impairment from the age of 6-8 years. They were mentally retarded, obese, and had hypogenitalism (Table 4). One member of family IX had a non-perceptive hearing impairment in one ear.

DIABETES MELLITUS

The two siblings in family $\mathrm{V}$ with hearing impairment and the female sibling in family $\mathrm{X}$ had impaired glucose tolerance. The latter had normal hearing.

OTHER PATHOLOGICAL CONDITIONS

One of each of the following additional disorders was registered in different patients: adenoma of the pituitary, clubfoot, anal cyst, cerebral stroke, and cancer of the testis.

Table 6 All clinical signs registered in two pairs of siblings in families VIII and IX with the disorder genetically linked to the BBS4 locus on chromosome 15

\begin{tabular}{|c|c|c|c|c|}
\hline \multirow[b]{3}{*}{ Sex } & \multicolumn{4}{|l|}{ Family } \\
\hline & \multicolumn{2}{|l|}{$V I I I$} & \multicolumn{2}{|l|}{$I X$} \\
\hline & $\mathrm{F}$ & $\mathrm{F}$ & $\mathrm{M}$ & $\mathrm{M}$ \\
\hline Age at examination (years) & 33 & 20 & 32 & 30 \\
\hline $\mathrm{H} / \mathrm{W} / \mathrm{BMI}$ & $157 / 118 / 44$ & $160 / 120 / 47$ & $178 / 96 / 30$ & $170 / 89 / 31$ \\
\hline Hypertension & + & - & + & + \\
\hline Brachydactyly & + & + & + & + \\
\hline Polydactyly & Foot & - & Hand & Hand \\
\hline Spinal stenosis & - & - & + & - \\
\hline Paraparesis & - & - & + & - \\
\hline Dental anomalies & + & + & + & + \\
\hline Mental retardation & + ? & $+?$ & - & - \\
\hline Small genitalia & - & - & + & + \\
\hline Irregular menstrual periods & + & + & & \\
\hline Adenoma of hypophysis & - & - & + & - \\
\hline Visual acuity & HM & HM & LP & HM \\
\hline Nystagmus & - & - & + & + \\
\hline Myopia & + & - & + & + \\
\hline Cataract & + & + & - & + \\
\hline Pale optic disc & + & + & + & + \\
\hline Attenuated retinal vessels & + & + & + & + \\
\hline Retinal bone spicules & $(+)$ & - & ++ & ++ \\
\hline
\end{tabular}

$\mathrm{H}=$ height $(\mathrm{cm}) ; \mathrm{W}=$ weight $(\mathrm{kg}) ; \mathrm{BMI}=$ body mass index; $\mathrm{HM}=$ hand movements; $\mathrm{LP}=$ light perception.
GENETIC LINKAGE MAPPING AND CHROMOSOME ANALYSIS

The present families are included in a larger study of linkage mapping in 29 BBS families. ${ }^{25}$ Our families are identified as BB12, 14, 18, 22, $23,24,25 / 26,27,28,30$, and 31 in this study. The values for probability of inclusion or exclusion of linkage to the BBS loci on chromosomes 11 (BBS1), 15 (BBS4), or 16 (BBS2) are shown in Table 5. No linkage was found in any of the families to the BBS locus on chromosome 3 (BBS3).

Statistical significance of genetic linkage (lod score 3 or more) was found to the BBS4 locus on chromosome 15 in the patients from family VIII and family IX. The clinical findings in each of these four patients are shown in Table 6. Probable evidence of linkage to the BBS4 locus was found for families III and X. The results for the remaining individual families were not informative.

High resolution chromosome analysis showed no abnormalities.

\section{Discussion}

Studies on recessive diseases in Scandinavia are constrained by low consanguinity rate and small number of children, which prevents statistical significance of the clinical and genetic results for each family. On the other hand the small and well defined Scandinavian populations facilitate follow up studies. Our study of 11 BBS families with two to three affected members is, to our knowledge, the largest seen by the same investigators.

The study describes the intrafamilial variation of the phenotype of the BBS by comparison of the affected siblings within each of these families.

It is our impression, that the individuals included in our study are representative of those patients who are diagnosed clinically. Like other authors ${ }^{17}$ we required three of the traditional cardinal signs (retinal dystrophy, obesity, polydactyly, hypogenitalism, mental retardation) for inclusion in the study, since hypogenitalism is mainly diagnosed in men and mental retardation has been questioned as being a cardinal sign. ${ }^{11}$ We accepted the statement by Schachat and Maumenee, ${ }^{20}$ that retinal dystrophy is always present in patients with BBS. All affected siblings had an abnormal ERG, while no signs of BBS were reported in the normal siblings. All the patients were diagnosed as BBS cases although overlapping to Laurence-Moon and Alström syndromes (or the closely related Edwards syndrome ${ }^{26}$ ) was observed. Overlapping to Laurence-Moon and Alström syndromes has been described in other BBS studies. ${ }^{13-15} 27$

The comparison of BBS siblings in our study showed intrafamilial variation for expressivity of obesity, skeletal anomalies of the extremities, hypogenitalism, short stature, paraplegia, dental abnormalities, and for the course of the retinal dystrophy. The clinical heterogeneity is more widespread within our BBS families than is reported by other authors ${ }^{11}$ who, however, described intrafamilial variation of mental retardation. In our study a low score by the 
intelligence test at school was not in accordance with the level of social performance later in life in the patients from families VII, X, and $\mathrm{XI}$, who all became self supporting. This change with age of the mental status in BBS individuals has also been noted by other authors. ${ }^{9}$ Our results on mental retardation must therefore be interpreted with caution and no statement on intrafamilial variation can be made.

We found variation of the time for onset of ocular symptoms and of the course of the retinal disease. The time for onset of the symptoms of the retinal dystrophy was precisely reported and was noted when the child missed its toys in dimmed light or was unable to play in dark places. The variation found in the families IV, VI, VII, VIII, and X (Table 2) was therefore based upon precise information mainly from the parents. In the family VII, for example, one sibling became simultaneously night blind and visually impaired during daytime, while another sibling had visual problems in daylight first and became night blind later, and the third had developed the symptoms in reverse order (Table 2). Such a variation of the onset of the symptoms of retinal dystrophy is, to our knowledge, noted for the first time.

The course of retinal dystrophy, illustrated by the rate of decline of visual acuity, varied in the two siblings in family IV (Fig 2). We found no variation of the fundus picture within families; however, clinically disparate phenotypes within the same family have been observed in patients with retinal dystrophy, who had a deletion in the peripherin/RDS gene. ${ }^{28}$

Intrafamilial variation of expressivity of clinical signs has also been described in the Cohen syndrome, ${ }^{29}$ which is closely related to BBS.

The result of genetic linkage mapping in each our 11 families was statistically significant for linkage to the BBS4 locus on chromosome 15 in two of the families and thus confirms earlier findings. ${ }^{17}$ Other authors have mapped BBS families to loci on chromosomes 3 (BBS2), ${ }^{18} 11$ (BBS1), ${ }^{16} 26$, and 16 (BBS3), ${ }^{19} 25$ and have indicated that even more genetic loci exist. ${ }^{25}$ The clinical findings in our chromosome 15 patients varied for nearly all aspects of the disorder. The polydactyly was localised to the foot or totally absent in family VIII and to the hand in family IX. The obesity was morbid in family VIII but was just beyond the normal (BMI 28) in family IX. We can therefore not confirm the results of Carmi and coworkers, ${ }^{30}$ who suggested that mutations at the BBS4 locus result in post axial polydactyly predominantly of the upper limbs. Dental anomalies and brachydactyly were common findings, but these features are generally noted in BBS patients, ${ }^{11}{ }^{24}$ and therefore do not contribute to the clinical characterisation of the chromosome 15 type.

The Bardet-Biedl syndrome has proved to be more clinically and genetically heterogeneous than earlier expected. No clinical features were found in our patients that could serve to distinguish the chromosome 15 linked families from the remaining material, and no clinical distinctions have been described for families linked to the other BBS loci. Leppert and coworkers $^{16}$ did not find any specific trait or subset of traits that could distinguish the subset of families with positive lod scores to chromosome 11 from the set with negative lod scores. Bruford and coworkers ${ }^{25}$ found no clinical distinctions between BBS1, BBS2, and BBS4 linked families in their material of 29 BBS families and suggested that the findings of Carmi and coworkers ${ }^{30}$ could relate more to specific mutations or to the inbred genetic background of their patients than to the BBS locus itself.

How can affected siblings, even within the same BBS family who must share the same mutation, show such a variation in phenotypes? Age or sex alone does not appear to explain the variation. However, inheritance of different alleles of other genes may either alleviate or aggravate the expression of the disease if the product of these, currently unknown, genes interacts with the disease genes of BBS.

The mechanism of the clinical and genetic diversity in BBS patients is not yet known. Further careful clinical and genetic studies of BBS families with several affected individuals can contribute to a better understanding of this complex disorder. This study was supported by grants from Hedmark County Norwegian LMBB Association, the Norwegian Ophthalmological Society, the Nycomed-Pharma Award, the Danish Association of the Blind, the Danish Society for Prevention of Blindation of the Blind, the Danish Society for Prevention of Blindness, International Retinitis Pigmentosa Association, Novo
Nordisk Foundation, the Danish Biotechnology Research and Nordisk Foundation, the Danish Biotechnology Research and
Development Programme (1991-95) and the University of Lund, Sweden.

1 Solis-Cohen S, Weiss E. Dystrophia adiposogenitalis with atypical retinitis pigmentosa and mental deficiency-the Laurence-Biedl syndrome. A report of four cases in one family. Am f Med Sci 1925;169:489-505.

2 Laurence JC, Moon RC. Four cases of 'retinitis pigmentosa' occurring in the same family, and accompanied by general imperfections of development. Ophthalmol Rev 1866;2:3241 .

3 Biedl A. Ein Geschwisterpaar mit adiposo-genitaler Dystrofie. Dtsch Med Wochenschr 1922;4:1630.

4 Bardet G. Sur un syndrome d'obésité congénitale avec polydactylie et rétinite pigmentaire (Contribution à l'étude des formes cliniques de l'obésité hypophysaire). These de Paris 1920;470:9-107.

5 Hutchinson J. Slowly progressive paraplegia and disease of the choroids with defective intellect and arrested sexual development in several brothers and a sister. Arch Surg 1900;11:118-22.

6 Franceschetti A, Klein D. Syndrome de Laurence-MoonBardet-Biedl. Rev Oto-Neuro-Ophthal 1948;20:109-14.

7 Alström CH, Hallgren BH, Nilsson LB, Åsander H. Retinal degeneration combined with obesity, diabetes mellitus and neurogeneous deafness. A specific syndrome (not hitherto described) distinct from the Laurence-Moon-Bardet-Biedl described) distinct from the Laurence-Moon-Bardet-Biedl
syndrome. A clinical, endocrinological and genetic examination based on a large pedigree. Acta Psychiatr Scand 1959; 34,Suppl 129:1-35.

8 Bell J. The Laurence-Moon syndrome. In: Penrose LS, ed. The treasury of human inheritance. London: Cambridge University Press, 1958; Vol 5:51-96.

9 Klein D, Ammann F. The syndrome of Laurence-MoonBardet-Biedl and allied diseases in Switzerland. 7 Neurol Sci 169;9:479-513.

10 Bergsma RB, Brown KS. Assessment of ophthalmologic, endocrinologic and genetic findings in the Bardet-Biedl syndrome. Birth Defect 1975;2:132-6.

11 Green JS, Parfrey PS, Harnett JD, Farid JD, Cramer BC, Johnson G, et al. The cardinal manifestations of BardetBiedl syndrome, a form of Laurence-Moon-Biedl syndrome. N Engl f Med 1989;321:1002-9.

12 Lavy T, Harris CM, Shawkat F, Thompson D, Taylor D. Electrophysiological and eye-movement abnormalities in children with the Bardet-Biedl syndrome. $f$ Pediatr Ophthalmol Strabismus 1995;32:364-7.

13 Rizzo JF, Berson EL, Lessell S. Retinal and neurologic findings in the Laurence-Moon-Bardet-Biedl phenotype. Ophthalmology 1986;93:1452-6. 
14 Hauser C, Rojas C, Roth A, Schmied E, Saurat H-H. A patient with features of both Bardet-Biedl and Alström syndromes. Eur f Pediatr 1990;149:783-5.

15 Escallon F, Traboulsi EI, Infante R. A family with the Bardet-Biedl syndrome and diabetes mellitus. Arch Ophthalmol 1989;107:855-7.

16 Leppert M, Baird L, Anderson KL, Otterud B, Lupski JR Lewis AL. Bardet-Biedl syndrome is linked to DNA markers on chromosome $11 \mathrm{q}$ and is genetically heterogeneous. Nature Genet 1994;7:108-12.

17 Carmi R, Rokhlina T, Kwitek-Black AE, Elbedour K, Nishimura D, Stone EM, et al. Use of a DNA pooling strategy to identify a human obesity syndrome locus on chromosome 15. Hum Mol Genet 1995;4:9-13.

18 Sheffield VC, Carmi R, Kwitek-Black AE, Rokhlina T, Nishimura D, Duyk GM, et al. Identification of a BardetBiedl syndrome locus on chromosome 3 and evaluation of an approach to homozygosity mapping. Hum Mol Genet an approach to

19 Kwitek-Black AE, Carmi R, Duyk GM, Buetow KH, Elbedour K, Parvari R, et al. Linkage of Bardet-Biedl syndrome to chromosome $16 \mathrm{q}$ and evidence for non-allelic genetic heterogeneity. Nature Genet 1993;5:392-6.

20 Schachat AP, Maumenee IH. Bardet-Biedl syndrome and related disorders. Arch Ophthalmol 1982;100:285-8.

21 Riise R, Andreasson S, Tornqvist K. Full-field electroretinograms in individuals with the Laurence-Moon-BardetBiedl syndrome. Acta Ophthalmol Scand 1996;74:618-20.

22 Lee PA, Mazur T, Danish R, Amrhein J, Blizzard RM, classification. fohns Hopkins Med f 1980;146:156-63.
23 Rudling O, Riise R, Tornqvist K, Jonsson K. Skeletal abnormalities of hands and feet in Laurence-Moon-Bardetmalities of hands and feet in Laurence-Moon-Bardet-
Biedl syndrome. A radiographic study. Skeletal Radiol Biedl syndrome.

24 Borgström MK, Riise R, Tornqvist K, Granath L. Anomalies in the permanent dentition and other findings in individuals with Laurence-Moon-Bardet-Biedl syndrome. f Oral Pathol Med 1996;25:86-9.

25 Bruford EA, Riise R, Teague PW, Porter K, Thomson KL, Moore AT, et al. Linkage mapping in 29 Bardet-Biedl syndrome families confirms loci in chromosomal regions 11q13, 15q22.3-q23 and 16q21. Genomics (in press).

26 Edwards JA, Sethi PK, Scoma AJ, Bannerman RM, Frohman LA. A new familial syndrome characterized by pigmentary retinopathy, hypogonadism, mental retardation, nerve deafness and glucose intolerance. Am $\mathcal{F ~ M e d}$ 1976;60:23-32.

27 Nyska M, Mozes G, Howard C, Bar-Ziv J, Dekel S. Quadriparesis in the Laurence-Moon-Bardet-Biedl syndrome: pare report. Paraplegia 1991;29:350-4.

28 Weleber RG, Carr RE, Murphey WH, Sheffield VC, Stone EM. Phenotypic variation including retinitis pigmentosa, pattern dystrophy, and fundus flavimaculatus in a single family with a deletion of codon 153 and 154 of the peripherin/RDS gene. Arch Ophthalmol 1993;111:1531-42.
Young ID, Moore JR. Intrafamilial variation in the Cohen syndrome. f Med Genet 1987;24:488-92.

30 Carmi R, Elbedour K, Stone EM, Sheffield VC. Phenotypic differences among patients with Bardet-Biedl syndrome linked to three different chromosome loci. Am f Med Genet 1995;59:199-203. 